УДК 629.463.12

Д-р техн. наук М.Б. Кельрих, кандидаты техн. наук Н.С. Брайковская, В.Н. Ищенко, асист. В.Е. Осьмак (ГЭТУТ)

Doct. of techn. sciences M.B. Kelrih, cand. of techn. sciences N.S. Braykovskaya, cand. of techn. sciences V.N. Ishchenko, assistant V.E Osmak

\title{
ТЕОРЕТИЧЕСКИЕ ОСНОВЫ РАЗДЕЛЬНОГО ОПРЕДЕЛЕНИЯ ПОКАЗАТЕЛЕЙ ТЕПЛОМАССООБМЕНА ПРИ ТЕПЛОТЕХНИЧЕСКИХ ИСПЫТАНИЯХ КРЫТЫХ ВАГОНОВ С ТЕПЛОИЗОЛЯЦИЕЙ
}

\author{
THEORETICAL BASIS OF SEPARATE DETERMINATION OF \\ INDICATORS FOR HEAT THERMAL TESTING COVERED WAGON \\ WITH THERMAL INSULATION
}

\begin{abstract}
Введение. Применение предварительной подготовки грузов к транспортировке в местах их производства или хранения не требует для создания и поддержания температурного режима перевозки использования подвижного состава с энергетической установкой. При этом возникает потребность в подвижном составе, который обеспечивает только пассивную защиту груза от воздействия атмосферных осадков и резких перепадов внешней температуры воздуха. Таким подвижным составом являются крытые вагоны с теплоизоляцией.
\end{abstract}

В настоящее время ведется разработка, производство и испытание крытых вагонов с теплоизоляцией, предназначенных для перевозки нескоропортящихся продовольственных штучных, тарно-штучных и пакетированных грузов, выполняются исследования теплотехнических характеристик с целью повышения теплоизоляционных качеств кузова.

Постановка задачи. Крытый вагон с теплоизоляцией представляет собой теплотехнические системы, в которых протекают различные по физической сущности процессы переноса, аккумуляции и освобождения тепловой энергии. Такие системы предназначены для сохранности груза путем поддержания заданных температурных условий в достаточно ограниченном диапазоне значений.

Границами теплотехнической системы крытого вагона с теплоизоляцией служат наружные поверхности ограждающих конструкций кузова, которые обладают определенными свойствами по отношению к проницаемости для потоков вещества и энергии. Защиту груза от воздействия внешней среды обеспечивает теплоизоляция кузова.

В практике производства, эксплуатации и ремонта вагонов оценку теплозащитных качеств кузова производят экспериментальным определением следующих характеристик: приведенного коэффициента теплопередачи и показателя герметичности кузова, оцениваемого различными критериями в зависимости от метода испытания. Определить приведенный коэффициент теплопередачи кузова при испытании вагона можно 
методами охлаждения или нагревания воздуха внутри грузового помещения. На практике чаще применяется метод нагревания воздуха внутри грузового помещения. Преимущество этого метода состоит в его простоте, так как теплопроизводительность электропечей, установленных внутри кузова, легко и быстро регулируются. Герметичность кузова чаще всего определяется измерением объема расхода воздуха через неплотности при создании в кузове постоянного стандартного избыточного давления 49 Па. Непосредственное измерение является важным достоинством этих теплотехнических характеристик. В рамках этих методов испытаний исключается раздельная оценка истинного (преимущественно) кондуктивного коэффициента теплопередачи и влияние воздухообмена через неплотности кузова вагона.

Анализ исследований и публикаций. На основании проведенного анализа литературных источников отечественных и зарубежных ученых и специалистов, технической документации на изотермические вагоны можно сделать вывод о необходимости дальнейших исследований по разработке и усовершенствованию методик, позволяющих определять теплотехнические показатели кузова крытых вагонов с теплоизоляцией по результатам теплотехнических испытаний.

Цель статьи. Изложение теоретических основ методики определения истинного коэффициента теплопередачи и площади эквивалентного отверстия фильтрации по результатам теплотехнических испытаний крытых вагонов с теплоизоляцией.

Основная часть. Кузов вагона с теплоизоляцией в теплотехническом отношении представляет собой довольно сложную пространственную систему. Наличие многочисленных металлических элементов довольно сложной геометрической формы в ограждающих конструкциях кузова делает практически невозможными точное расчётное определение коэффициента теплопередачи кузова. Абсолютная плотность кузова вагона практически невозможна, поэтому теплопередача через ограждение конструкции сопровождается процессами неорганизованного естественного воздухообмена, называемыми фильтрацией (инфильтрация и эксфильтрация). Эти процессы вызывают дополнительные теплопритоки (теплопотери) и ухудшают теплозащитные свойства кузова.

Суммарный тепломассообмен между воздухом в грузовом помещении кузова и внешней средой происходит за счет кондуктивной передачи и воздухообмена через неплотности ограждений кузова.

Основное уравнение теплопередачи для стационарных условий теплообмена при теплотехнических испытаниях вагона методом нагревания воздуха в грузовом помещении можно записать в виде теплового баланса [1]

$$
Q=K_{n p} \cdot F\left(T_{B}-T_{H}\right) \text {, }
$$

где $Q$ - тепловой поток через ограждение кузова вагона, Вт;

$K_{n p} \quad$ - приведенный коэффициент теплопередачи, Вт $/ \mathrm{M}^{2} \mathrm{~K}$;

$F$ - среднегеометрическое значение площади поверхности кузова, $\mathrm{m}^{2}$;

$T_{B}$ - средняя температура воздуха в грузовом помещении, К;

$T_{H}$ - средняя температура наружного воздуха, $\mathrm{K}$.

Приведенный коэффициент теплопередачи определяется по формуле [2]

$$
K_{n p}=\beta \cdot \bar{K}
$$

где $\bar{K}$ - истинный коэффициент теплопередачи, усредненный по поверхности вагона, Вт/м ${ }^{2} \mathrm{~K}$; 
$\beta$ - коэффициент эксфильтрации, учитывающий увеличение теплопотерь через ограждения за счет воздухопроницаемости кузова.

Истинный (преимущественно кондуктивный) коэффициент теплопередачи кузова вагона, усредненный по поверхности, определяется по формуле [2]

$$
\bar{K}=\frac{1}{F} \sum_{i=1}^{n} K_{i} \cdot F_{i}
$$

где $K_{i} \quad$ - локальный $\quad$ коэффициент теплопередачи і-го участка кузова, Вт/м ${ }^{2} \mathrm{~K}$;

$F_{i}$ - средняя площадь теплопередачи іго участка кузова, $\mathbf{m}^{2}$.

Наиболее характерными показателями герметичности кузова вагона при теплотехнических испытаниях является коэффициент эксфильтрации $\beta$ и площадь эквивалентного отверстия $F_{\text {экв }}$. Коэффициент $\beta$ непосредственно показывает дополнительные теплопотери за счет эксфильтрации воздуха, однако его величина не является стабильной, так как зависит от разности температур в вагоне и окружающей среды. Это значит, что для использования $\beta$ в качестве критерия герметичности необходимо регламентировать температурные режимы, при которых оцениваются теплопритоки кондукцией и эксфильтрацией.

Площадь эквивалентного отверстия $F_{\text {экв }}$ является геометрической характеристикой герметичности и наиболее естественным показателем герметичности.

Для определения $\bar{K} \quad$ и $F_{\text {экв }}$ по результатам теплотехнических испытаний вагона методом нагревания воздуха внутри грузового помещения и определения расхода воздуха через отверстия фильтрации разработана математическая модель, которая отображает связь термодинамических параметров при испытаниях в системе «Грузовое помещение кузова - теплоноситель - кузов - окружающая среда» (ГПК - Т - Л - ОС).

На основании проведенных теоретических исследований математическая модель системы (ГПК - Т - Л - ОС) с учетом теплового процесса нагревания воздуха в грузовом помещении кузова вагона и измерения объема расхода воздуха через неплотности при создании в кузове постоянного стандартного избыточного давления описывается системой уравнений $[1,2,3]$.

В этой связи возникает потребность в создании методик, позволяющих на базе существующих методов теплотехнических испытаний раздельно определять показатели кондуктивной передачи теплоты и воздухообмена через неплотности кузова вагона.

Расход воздуха через отверстия фильтрации при испытании кузова на герметичность

$$
\left\{\begin{array}{l}
L_{c m}=\omega_{c m} \cdot F_{\text {экв }} \\
\omega_{c m}=\sqrt{\frac{2 \Delta p}{\rho}} \\
F_{\text {экв }}=\frac{L_{c m}}{\omega_{c m}}
\end{array}\right.
$$

где $L_{c m^{-}}$объемный расход воздуха через отверстия фильтрации при избыточном давлении $\Delta p, \mathrm{~m}^{3} / \mathrm{c}$;

$\omega_{c m}$ - скорость воздуха через отверстие фильтрации при избыточном давлении $\Delta p$, $\mathrm{M} / \mathrm{c}$;

$F_{\text {экв }}-$ площадь эквивалентного отверстия фильтрации в ограждении кузова, $\mathbf{m}^{2}$;

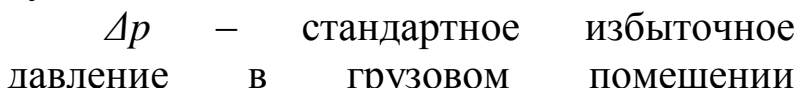
кузова, Па;

$\rho$ - плотность воздуха, кг/м². 
Алгоритм методики раздельного определения показателей кондуктивной передачи теплоты и воздухообмена через неплотности при теплотехнических испытаниях крытого вагона с теплоизоляцией представлена в виде схемы на рисунке.

\section{Исходные данные \\ $\left\{T_{H}, \varphi_{H}, P_{h}, h_{H}, \rho_{h}, T_{B}, \varphi_{B}, P_{B}, \rho_{B}, F\right\}$}

\section{Параметры полученные при испытаниях}

Температура окружающего воздуха, $T_{н}$;

Температура воздуха в грузовом помещчении вагона, $T_{в}$;

$\left\{\right.$ Расход электроэнергии, $W_{н \eta}$;

Приведенный коэффициент теплопередачи, $K_{n p}$;

Объмньй расход воздуха через отверстие фильтращии, $L_{c m}$.

$$
\begin{aligned}
& \text { Решение } \\
& F_{\text {экв }}=\frac{L_{c m}}{\omega}, \\
& \omega_{c m}=\sqrt{\frac{2 \Delta P}{\rho}} \\
& \left\{Q_{f}=F_{\text {экв }} \cdot \rho_{\theta} \sqrt{2\left(h_{\theta}-h_{H}\right)}\right\} \\
& Q=W_{\text {ни }}+Q_{f} \\
& \bar{K}=\frac{Q}{F\left(T_{\theta}-T_{H}\right)}
\end{aligned}
$$

\section{Результаты}

$\left\{\begin{array}{l}\text { Истинный коэффищуиент теплопередачи кузова вагона, } \bar{K} \\ \text { Площуадь эквивалентногоотверстия фильтрации, } F_{\text {экв }}\end{array}\right\}$

Рис. Схема алгоритма раздельного определения показателей тепломассообмена при теплотехнических испытаниях вагона

\section{Выводы}

1. На основании теоретических исследований разработана математическая модель системы «грузовое помещение вагона - теплоноситель - кузов - окружающая среда», отображающая связь термодинамических параметров при теплотехнических испытаниях вагонов методом нагревания воздуха в грузовом помещении и измерение объема расхода 
воздуха при создании в вагоне нормированного избыточного давления.

2. На основании математической модели разработана методика раздельного определения показателей кондуктивной передачи теплоты и воздухообмена через неплотности при теплотехнических испытаниях крытого вагона с теплоизоляцией.

3. Разработанная методика позволяет по результатам теплотехнических испытаний и использования несложных расчетов определить истинный (преимущественно кондуктивный) коэффициент теплопередачи, усредненный по поверхности кузова, и площадь эквивалентного отверстия фильтрации, которые являются наиболее характерными показателями теплотехнических качеств кузова вагона.

\section{Список литературы}

1. Бартош, Е.Т. Энергетика изотермического подвижного состава [Текст] / Е.Т. Бартош. - М.: Транспорт, 1976. - 304 с.

2. Левенталь, Л.Я. Энергетика и технология хладотранспорта [Текст]: учеб. пособие для вузов железнодорожного транспорта / Л.Я. Левенталь, Н.Е. Лысенко, Д.И. Сучков, А. Хенаг; под ред. Л.Я. Левенталя. - М.: Транспорт, 1993. - 228 с.

3. Китаев, Б.Н. Теплообменные процессы при эксплуатации вагонов [Текст] / Б.Н. Китаев. - М.: Транспорт, 1984. - 184 с.

4. Недужний, И.А. Техническая термодинамика и теплопередача [Текст] / И.А. Недужний, А.Н. Алабовский. - К.: Вища школа, 1987. - 224 с.

5. РД 24.050.65-89. Вагоны рефрижераторные. Методика проведения теплотехнических испытаний [Текст]. - М., 1989.

Ключевые слова: крытый вагон с теплоизоляцией, тепломассообмен, теплотехнические испытания, коэффициент теплопередачи, фильтрация, показатель герметичности.

\section{Аннотации}

Стаття розкриває теоретичні основи роздільного визначення показників тепломасообміну критих вагонів 3 теплоізоляцією за результатами випробувань i використання нескладних теплотехнічних розрахунків.

Статья раскрывает теоретические основы раздельного определения показателей тепломассообмена крытых вагонов с теплоизоляцией по результатам испытаний и использования несложных теплотехнических расчетов.

The article reveals the theoretical basis of the separate determination of heat and mass transfer performance of covered wagons with insulation on the test results and the use of simple thermal calculations. 